\title{
Operational Mechanism and Evaluation System for Emergency Logistics Risks
}

\author{
Qi Cheng \\ School of Management, WHUT, Wuhan, China \\ Email:lindachq@gmail.com \\ Lei $\mathrm{Yu}$ \\ School of Management, WHUT, Wuhan, China \\ 18971611031@189.cn
}

\begin{abstract}
Lots of risks existed in the operating process of emergency logistics especially when natural disasters happened. Both operating mechanism and evaluation system research on Emergency Logistics Risks (ELR) are the basis of effective recognizing, preventing and responding to risks, so it's of great theoretical and practical significance to study the formation and influence mechanism and to establish an evaluating index system for ELR. Firstly, some foundation research about ELR was carried out, including definition, characteristics and classification of ELR. The formation and influence mechanism of ELR were discussed. The research of questionnaire survey offered an objective support for theoretical mechanism and index system establishment. Then, the evaluating index system for ELR was established. This system was a multi-level index system, and mainly evaluated by the decision-making risk, dispatching and commanding risk, organizing and coordinating risk, executing and controlling risk, resources supporting risk and their sub index. The establishment principles and significance of the index system were discussed. Then, the fuzzy comprehensive evaluation and Delphi method were used to confirm the index weight and value. Finally, a case analysis on ELR of Yushu earthquake was conducted to demonstrate the evaluating index system and to evaluate the actual risk level.
\end{abstract}

Index Terms-natural disaster, emergency logistics risk, operational mechanism, evaluation system

\section{INTRODUCTION}

Due to the features of derived, undercurrent and destructive, natural disasters bring unpredictable risks to the operation of Emergency Logistics Management System (ELMS), and test the operation ability of this system. So it becomes an important task for state controllers to discover, prevent and pre-control Emergency Logistics Risks (ELR). Till now, the literature research on the ELR has been seldom found. And from the research on logistics risks, it's not difficult to find that (1) the topics were basically involved in the identification, assessment and controlling of logistics risks[1 6]; (2) research objects were mainly large-scale manufacturing

Supported by "the Fundamental Research Funds for the Central Universities (Research on the Coupling Mechanism and Early-warning Management System for Natural Disasters Emergency Logistics Risks)". enterprises, production enterprises, retail industry, custom house, the third and fourth party logistics enterprises, etc[7 14]; (3) the emphasis were focused on logistics outsourcing risk, cooperation risk and supply chain risks[15 19]. These research exposed such problems as: (1) A systematic and comprehensive theoretical framework of Logistics Risk Management has not been built yet; (2) Factors system of logistics risks lack completeness; (3)In the aspect of logistics risk assessment, no complete evaluation index system from the angle of risk source and risk consequence has been created, nor an appropriate assessment method been selected. Besides, in the field of disaster risk controlling, it's difficult to find the research on the uncertainty factors which would affect the realizing of emergency logistics goals, and especially those problems caused by catastrophes. Therefore, it's urgent to find out the operating mechanism of ELR and to establish a workable index system to meet the demand of rapidly identifying, accurately evaluating, timely managing, and timely monitoring risks.

\section{OPERATIONAL MECHANISM OF EMERGENCY LOGISTICS RISKS}

\section{A. Meaning and Characteristics of Emergency Logistics Risks}

According to Risk Theory, risk means the uncertainty that will affect the realization of organization objectives. So, Emergency Logistics Risks, a special kind of risks in the field of disaster emergency logistics, mean the uncertainty that exposes the ELMS to risks caused by risk accidents. The risk accidents are caused by variety of risk factors, and affect the achievements of expected objectives of ELMS. Risk factors are precondition of risk accidents; risk accidents are accidents produced by variable changes within and outside the system, connecting risk factors and risk results.

Four dominant characteristics are attached to ELR:

1)Uncertainty and predictability of the occurrence: The occurrence and loss of ELR often appear accidentally and uncertainly. So it's usually not easy for the subject of ELMS to judge and estimate the answers to whether, when, where, what scale and what consequence that the ELR event will happen or make. However, there is a pattern in things' development, with the improvement of 
people's technology and knowledge, the pattern of ELR can be mastered, too. With some advanced techniques and more knowledge or data, the frequency and scope of ELR will be predicted to some extent.

2)Timeliness and variability of the occurrence and existence: ELR usually happened all of a sudden, difficult to identify and kept a rapid pace of change, so we demand a real-time monitoring, a high speed responding and a perfect accuracy of disposing. ELR's variability is reflected in both quality and quantity, the decrease in extent of losses caused by the risk is quantitative, while the new risk caused by the old ones is qualitative.

3)Elusiveness and correlation of the existence: Some kinds of ELR are very secluded and difficult to identify, while some kinds occur and develop by leaps and bounds with a short life cycle. Then, it's very difficult to control the risk once noticed. On the other hand, in the emergency state of disaster, with a complex and ambiguous relationship, the ELR may exist in one or several levels and links of the Emergency Logistics.

4)Controllability of the factors: Risk factors' accumulation and certain conditions are needed in ELR's occurrence. If the accumulation and necessary conditions can be controlled, the risks' occurrence will be stopped. If some measures can be taken to change the conditions of risks' occurrence, the risks may be resolved by transformation, even be defused.

\section{B. Causes and Categories of Emergency Logistics Risks}

A few researches were found about the classification, but Zhou $\mathrm{Yu}$ [20] thought that ELR consisted of emergency materials risk, emergency logistics (EL) institution risk, EL transport system risk and EL information risk; Zhao Yong [21] held the view that ELR was made up of technical risk, environment risk, management risk and operation risk.

To reveal the logical relations of factors that causing ELR, this paper firstly divided the ELR into five types, namely, decision-making risk, dispatching and commanding risk, organizing and coordinating risk, executing and controlling risk, resources supporting risk. Besides, according to the value chain theory, the process of emergency logistics can be regarded as the value added process of emergency rescuing supplies, including time efficiency, space efficiency, staff efficiency and supply efficiency are added to the rescuing supplies, in which the supply efficiency is made up of rescuing supplies efficiency and equipment efficiency. ELR will affect the play of these efficiencies. The categories of ELR and their contributing factors, as well as the aspects in which ELR will affect the supply value are summarized in table 1 .

Among them:

1) Decision-making risk: is the possibility of the defective early-warning system or the decision-makers' lack of quality and management skills that will lead to decision-making errors. Decision-makers risk, specific plans lacking risk, experts selecting risk and earlywarning system risk contribute to decision-making risk, which will affect the entire process through the effects on time efficiency, space efficiency, staff efficiency and supply efficiency. As a result, measures should be taken to overcome it at first.

2) Dispatching and commanding risk: is the possibility of the defective management system, scattered distribution of areas and the lack of resources that will lead to the low efficiency of Emergency Logistics. Victims' distribution risk, emergency transport capacity risk, scheduling risk and commanding risk contribute to dispatching and commanding risk, which is an important factor that has effects on the time efficiency, space efficiency and staff efficiency.

TABLE I.

CATEGORIES AND CAUSES OF EMERGENCY LOGISTICS RISKS

\begin{tabular}{|c|c|c|}
\hline Categories & Causes & Value effects \\
\hline $\begin{array}{l}\text { Decision-making } \\
\text { risk }\end{array}$ & $\begin{array}{l}\text { Decision-makers risk, specific } \\
\text { plans lacking risk, experts selecting } \\
\text { risk, early-warning system risk }\end{array}$ & $\begin{array}{l}\text { Time efficiency } \\
\text { Space efficiency } \\
\text { Staff efficiency } \\
\text { Supply efficiency }\end{array}$ \\
\hline $\begin{array}{l}\text { Dispatching \& } \\
\text { commanding risk }\end{array}$ & $\begin{array}{l}\text { Victims' distribution risk, } \\
\text { emergency transport capacity risk, } \\
\text { scheduling risk, commanding risk }\end{array}$ & $\begin{array}{l}\text { Time efficiency } \\
\text { Space efficiency } \\
\text { Staff efficiency }\end{array}$ \\
\hline $\begin{array}{l}\text { Organizing \& } \\
\text { coordinating risk }\end{array}$ & $\begin{array}{l}\text { Administration risk, military-local } \\
\text { cooperation risk, regional support } \\
\text { risk, national mobilization risk }\end{array}$ & Staff efficiency \\
\hline $\begin{array}{l}\text { Executing \& } \\
\text { controlling risk }\end{array}$ & $\begin{array}{l}\text { Personnel status risk, personnel } \\
\text { behaviors risk, personnel ability } \\
\text { risk }\end{array}$ & $\begin{array}{l}\text { Time efficiency } \\
\text { Supply efficiency }\end{array}$ \\
\hline $\begin{array}{c}\text { Resources } \\
\text { supporting risk }\end{array}$ & $\begin{array}{l}\begin{array}{l}\text { Environment influence and threat, } \\
\text { availability of transportation } \\
\text { network }\end{array} \\
\begin{array}{l}\text { Supplies risk, conveyance risk, } \\
\text { funds risk, communication risk, } \\
\text { etc. }\end{array}\end{array}$ & Supp \\
\hline
\end{tabular}

3) Organizing and coordinating risk: is the possibility of divergences in cooperation. Administration risk, military-local cooperation risk, regional support risk and national mobilization risk contribute to organizing and coordinating risk, which is the key factor that affects staff efficiency.

4) Executing and controlling risk: is the possibility of the instruction's executing error, processes' controlling failure and staff's bad state or behaviors that lead to the difference between the plan and result. Personnel status risk, personnel behaviors risk and personnel ability risk contribute to executing and controlling risk, which is a main factor that affects supply efficiency and time efficiency.

5) Resources supporting risk: is the possibility of the secondary disaster and environment damage caused by the disasters that result in the damage of logistics facilities, equipment and supplies. Resources supporting risk can be divided into two parts which affect the supply efficiency. Environment influence and threat as well as risk of transportation network availability contribute to one part, while emergency supplies risk, conveyance risk, emergency funds risk, communication and information risk contribute to the other part.

\section{C.Influence Mechanism of Emergency Logistics Risks}

Decision-making risk is the primary factor of ELR that has effects on the entire emergency logistics process. Take the procurement delays for example, the decision- 
makers' error in the judgment of purchasing time may not only lead to the effects on timeliness of getting supplies caused by the decline of time efficiency, but also result in some additional work to make up the loss caused by time delays. Similarly, decision-making risk may also lead to some other risk events such as lack of distribution, lack of specific plans and unreasonable distribution of nodes, which then result in the consequences including the supplies' arrival delays, quantity lacks and category errors.

Dispatching and commanding risk affects all aspects of emergency logistics through the staff dispatching errors, transportation and distribution delays, then logistic works fall into chaos with low efficiency. Take the staff dispatching errors for example, once the overworked staff is still arranged to work overtime in the front line, the science and rationality of instructions or dispatching and commanding plans are sure to be affected, even some commanding mistakes would be made, leading to serious effects on emergency logistics' effectiveness, efficiency and normal operation. Similarly, the traffic block caused by dispatching and commanding risk may also lead to supplies' arrival delays, etc.

Organizing and coordinating risk affects the time efficiency of emergency logistics by reducing the efficiency of human resources. Disaster emergency logistics are teamwork with several subjects, including fire officers, medical teams, logistics companies and volunteers. Once organizing and coordinating risks break out, subjects' works will be restricted by each other, affecting not only the whole effectiveness, but also the independent work, leading to the result that the corporate effectiveness is than the sum of independent ones. In the case of fire officers and logistics companies' cooperation, fire officers are responsible for repairing the broken transportation, while the logistics companies transport the related supplies for supporting. Once an organizing and coordinating error comes out, logistics companies' transportation delays will lead to the lag of fire officers' repairing works, which affect other transportations in return, causing disorders.

Executing and controlling risk's outbreak will not only affect EL's normal operation, but also lead emergency logistics to get out of the planning track, resulting in more risk accidents. For example, in the procurement chaos after disasters, lax execution and control would lead to the accidents of procuring staff's shoddy or supply lacks, resulting in the consequence that the supplies cannot meet victims' requirements.

Resources supporting risk affects rescuing supplies, logistics equipment, logistics channels and network, leading to quality, quantity and timeliness problems. The resources supporting risk's outbreak will mainly cause some risk accidents such as transportation channels' destroy, transportation equipment, communication tools and rescuing supplies' damage. Take the communication tool's damage for example, the lag of information transmission have direct effects on other management works such as organization \& coordination and dispatching \& command, caused the delays of procurement and distribution, leading to effects on the timeliness of supplies gaining in disaster area.

Influence mechanism of the risks can be demonstrated as Fig. 1:

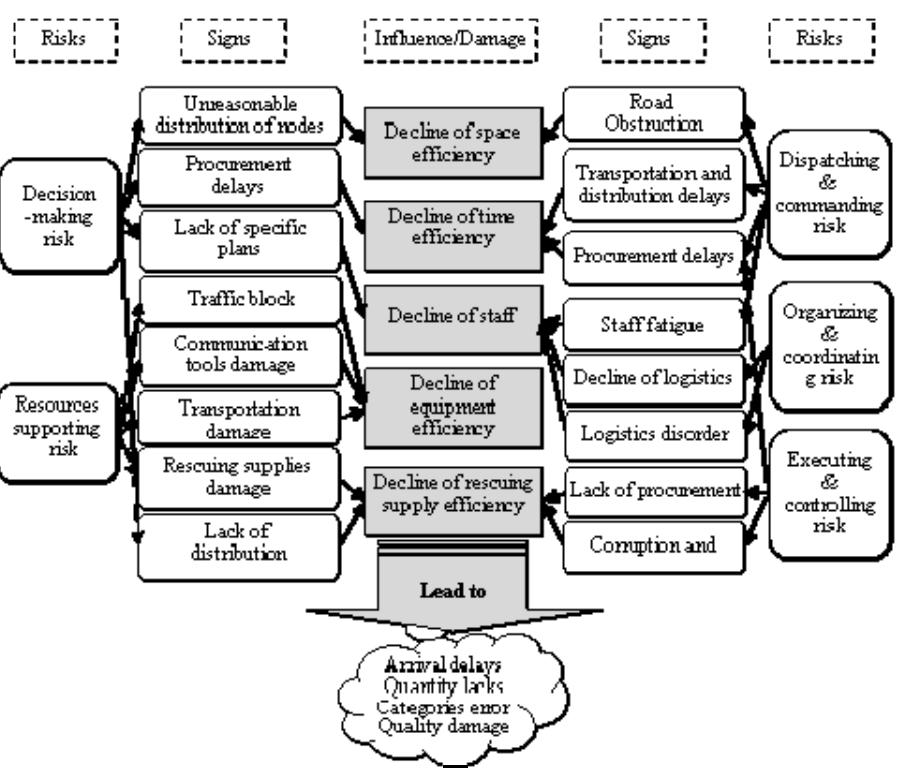

Figure1. Influence mechanism Emergency Logistics Risks

\section{D.Questionnaire Survey}

In order to further understand the operational mechanism of ELR and to identify key risk factors, and to better prevent ELR, Methods An anonymous questionnaire was conducted among 120 scholars home and abroad in the logistics field which resulted in $75.0 \%(90)$ sample return and an effective rate of $96.7 \%(87)$.

1) Possibility and severity of Emergency logistics risks: Equation (1) indicates the connotation of risk. According to this equation and using the Likert Scale (each item adopted the 5-degree scoring), we chose 26 possible risk events, and invited the respondents to give their judgments. Respondents scored for the possibility of risk events (as Fig. 2 7) and the severity of events consequence (as Fig.8).

Risk $=$ probability of event $*$ event consequence 


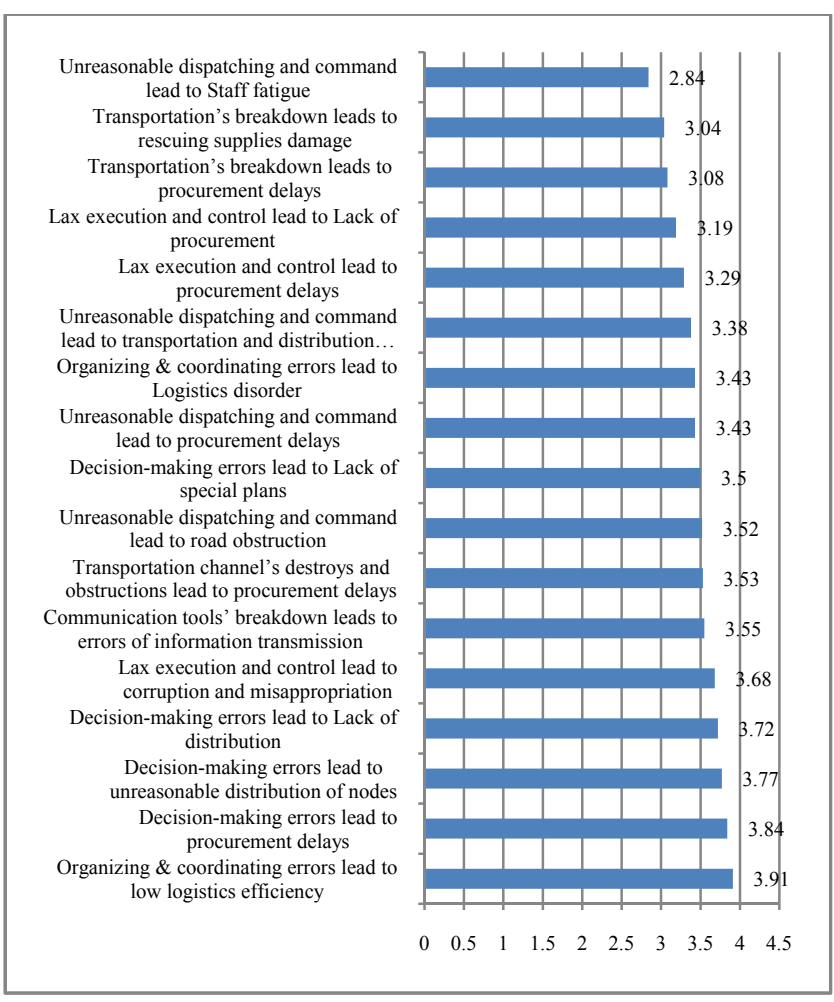

Figure 2. Possibility of emergency logistics risk events

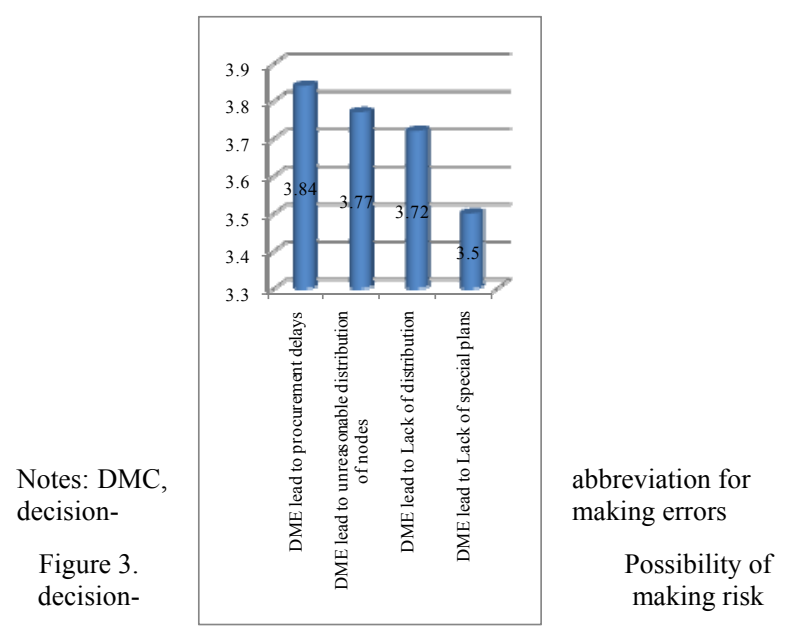

Notes: OCE, abbreviation for organizing \& coordinating errors
Figure 4. Possibility of organizing \& coordinating risk

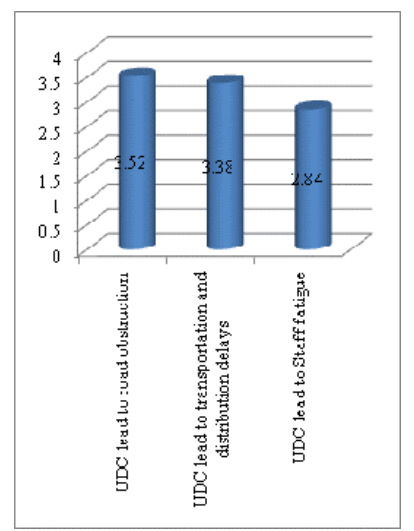

Notes: UDC, abbreviation for unreasonable dispatching and command

Figure 5. Possibility of organizing \& coordinating risk

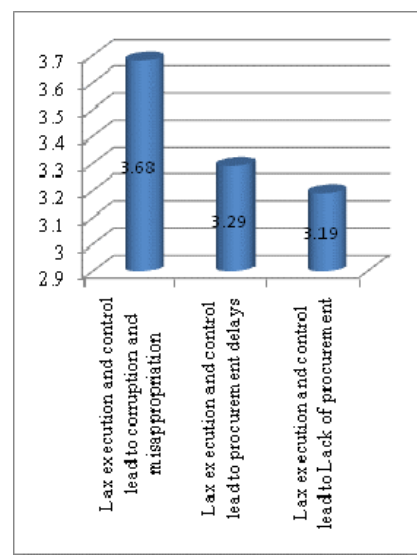

Figure 6. Possibility of executing \& controlling risk

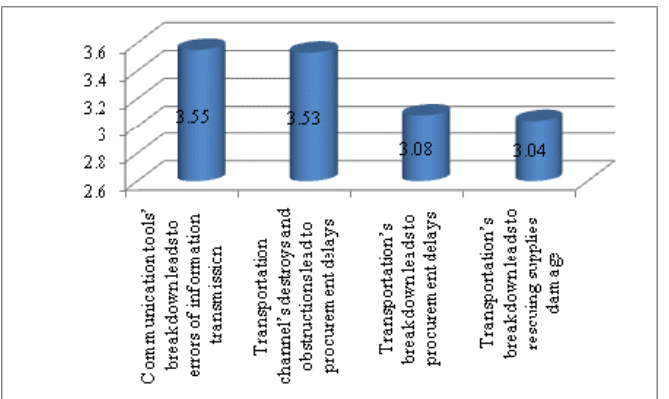

Figure 7. Possibility of dispatching \& commanding risk

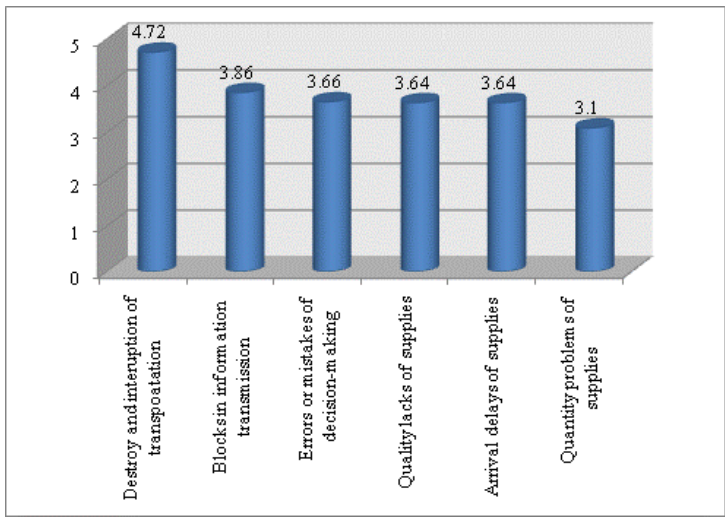

Figure 8 . Severity of typical risk consequences 
It's easy to find out:

Firstly, from the perspective of overall five risks, we can find that the respondents generally thought decisionmaking's outbreak of greatest possibility. It's less possible for dispatching \& commanding risk and organizing \& coordinating risk to break out.

Secondly, from the perspective of single risk accident, it's of greatest possibility for the organizing and coordinating error leading to the decline of EL efficiency, accidents of procurement delays, procurement violations, logistic nodes' unreasonable distribution caused by decision-making errors and corruption, misappropriation caused by executing \& controlling failure are followed.

Finally, less possible though the accidents of EL efficiency's decline caused by the destroy of transportation channels and communication tools are regarded, due to the serious consequence they would lead to, this two risk accidents should be prevented strictly, too.

2) Key factors of Emergency Logistics Risks: Risk factors were summarized into 26 ones in the questionnaire, respondents scored for the key degree of each one (The scores were converted into hundred mark system in the statistics). Results show that the degree of transportation's damage and disruption, reliability of EL dispatching and commanding, rationality of rescuing repositories' distribution and timeliness of government's Emergency response are the most key factors; a complete and reliable EL specific plan, the disaster's complexity, size of disaster area, quantity of victims, the participation of military logistics force and special EL management agencies are followed. The convey results are shown in table 2 below:

TABLE II.

KEY DEGREE OF RISK FACTORS

\begin{tabular}{|c|c|c|}
\hline \multicolumn{2}{|r|}{ Risk factors } & Key degree \\
\hline 1) & Degree of transportation's damage and disruption & 96.6 \\
\hline 2) & Reliability of EL dispatching and commanding & 94.8 \\
\hline 3) & Rationality of rescuing repositories' distribution & 93.1 \\
\hline 4) & Timeliness of government's Emergency response & 93.1 \\
\hline 5) & A complete and reliable EL specific plan & 91.4 \\
\hline 6) & Participation of military logistics force & 89.7 \\
\hline 7) & Size of disaster area & 89.7 \\
\hline 8) & The disaster's complexity & 89.7 \\
\hline 9) & Quantity of victims & 87.9 \\
\hline 10) & Special EL management agencies & 87.9 \\
\hline 11) & Rationality of EL center's location and function & 86.2 \\
\hline 12) & Completeness of EL laws and regulations & 86.2 \\
\hline 13) & The disaster's destruction & 86.2 \\
\hline & Shortage of emergency supplies & 86.2 \\
\hline & $\begin{array}{l}\text { Reliability(accuracy, openness and timeliness) of } \\
\text { materials' supply and demand information }\end{array}$ & 86.2 \\
\hline 16) & Rationality of transport choice & 86.2 \\
\hline & Reliability of rescuing supplies provider & 84.5 \\
\hline & Effects of Logistics industry organizations & 84.5 \\
\hline
\end{tabular}

\begin{tabular}{|ll|c|}
\hline 19$)$ & The normal operation of logistic equipment & 84.5 \\
\hline 20$)$ & Physical state of the relevant staff & 84.5 \\
\hline 21) & Effects of secondary disaster's destruction & 84.4 \\
\hline 22$)$ & $\begin{array}{l}\text { Authority of government emergency response } \\
\text { agency }\end{array}$ & 84.4 \\
\hline 23) & Reliability of community donations & 75.8 \\
\hline 24$)$ & Choice of experts & 74.6 \\
\hline 25$)$ & Insurance products established specially for EL & 73.2 \\
\hline 26$)$ & Participation of social logistic enterprise & \\
\hline
\end{tabular}

\section{CONSTRUCTION OF EVALUATING INDEX SYSTEM}

\section{A.Construction Significance of Evaluating Index System}

Risks are potential threats to ELMS, testing ELMS's operational capabilities. So, it's necessary to monitor, identify, analyze, and control risk factors before risk accumulation degree would badly affect ELMS. The establishment of evaluating index system for ELR could acquaint state controllers with potential risks, and confirm doable approaches to decrease risk rate according to actual index value. All these efforts aim to help ELMS run and develop in a safer and steadier way.

\section{B.Construction Principles of Evaluating Index System}

The evaluation on ELR is to identify an individual or several key factors of ELR on the information collected, thus to provide a scientific decision and management basis, and to meet the emergency supplies' demand of disaster-stricken areas in the shortest time. Therefore, in the evaluation process, the following principles should be paid attention to:

1)Scientific and objective: The assessment should be consistent with objective reality, which can reflect the degree of ELR wholly and truly, and can ensure results accurate.

2)Comprehensive and representative: All the key factors constituting ELR and thire relationship should be considered. The index should be concise, representative, without missing.

3)Practicable and Measurable: The system should have a clear logic, distinct levels to make sure that the evaluation value can be acquired accurately and quickly, and each indicator in the system is applicative to quantitative analysis.

4)Relevant and dynamic: A variety of internal relations in the practical management work should be reflected, as well as the risks' dynamic characteristic.

\section{C.Framework of Evaluation Index System}

Based on above formation research on ELR and establishing principles, the framework of evaluating index system for ELR could be confirmed by the method of Delphi (see Tab. 2). Considering risk probability and loss represented by various indicators, the method of Priority Sequence Table was used to screen indicators, and finally, the evaluating index system was confirm, as table 2 describes, including target layer, factor layer and index layer, a total of 23 indexes. 
TABLE III.

FRAMEWORK OF EVALUATING INDEX SYSTEM

\begin{tabular}{|c|c|c|}
\hline Target l & Factor layer & Index layer \\
\hline \multirow{23}{*}{$\begin{array}{l}\text { Evaluating } \\
\text { Index } \\
\text { System } \\
\text { Of } \\
\text { ELR } \\
\text { R }\end{array}$} & \multirow{4}{*}{$\begin{array}{l}\text { Decision- } \\
\text { making } \\
\text { risk } \mathrm{R}_{1}\end{array}$} & $\begin{array}{l}\text { Decision-makers' poor experience and } \\
\text { limited ability } R_{11}\end{array}$ \\
\hline & & \begin{tabular}{|lll} 
Lack of specific emergency logistics \\
plans $\mathrm{R}_{12}$
\end{tabular} \\
\hline & & $\begin{array}{l}\text { Experts with poor authoritative influence } \\
\mathrm{R}_{13}\end{array}$ \\
\hline & & \begin{tabular}{|l}
$\begin{array}{l}\text { Forewarning Information lacking high } \\
\text { accuracy } \mathrm{R}_{14}\end{array}$ \\
\end{tabular} \\
\hline & \multirow{5}{*}{$\begin{array}{l}\text { Dispatching } \\
\text { and } \\
\text { commanding } \\
\text { risk } \mathrm{R}_{2}\end{array}$} & Scattered distribution of disaster area $\mathrm{R}_{21}$ \\
\hline & & Lack of emergency transport capacityR $\mathrm{R}_{22}$ \\
\hline & & Unscientific scheduling schemes $R_{23}$ \\
\hline & & Improper scheduling arrangements $\mathrm{R}_{24}$ \\
\hline & & Multiple-headed commanding $\mathrm{R}_{25}$ \\
\hline & \multirow{4}{*}{$\begin{array}{l}\text { Organizing } \\
\text { and } \\
\text { coordinating } \\
\text { risk } \mathrm{R}_{3}\end{array}$} & $\begin{array}{l}\text { Unreasonably established administration } \\
\mathrm{R}_{31}\end{array}$ \\
\hline & & $\begin{array}{l}\text { Poor communication between military } \\
\text { and civilian } R_{32}\end{array}$ \\
\hline & & $\begin{array}{l}\text { Difficulties in cross-regional deployment } \\
\mathrm{R}_{33}\end{array}$ \\
\hline & & Inadequate national mobilization $R_{34}$ \\
\hline & \multirow{4}{*}{$\begin{array}{c}\text { Executing and } \\
\text { controlling } \\
\text { risk } \mathrm{R}_{4}\end{array}$} & Command to lose efficacy $\mathrm{R}_{41}$ \\
\hline & & Slow action $\mathrm{R}_{42}$ \\
\hline & & Fatigue operation $\mathrm{R}_{43}$ \\
\hline & & Irregular operation $\mathrm{R}_{44}$ \\
\hline & \multirow{6}{*}{$\begin{array}{l}\text { Resources } \\
\text { supporting } \\
\text { risk } R_{5}\end{array}$} & $\begin{array}{l}\text { Continuous secondary disasters and bad } \\
\text { weather } R_{51}\end{array}$ \\
\hline & & Insufficient means of transport $\mathrm{R}_{52}$ \\
\hline & & $\begin{array}{l}\text { Damaged degree of transport channel } \\
\mathrm{R}_{53}\end{array}$ \\
\hline & & \begin{tabular}{|l}
$\begin{array}{l}\text { Shortage of emergency funds and } \\
\text { materialsR }\end{array}$ \\
\end{tabular} \\
\hline & & $\begin{array}{l}\text { Breakdown of communication \& } \\
\text { information networks } \mathrm{R}_{55}\end{array}$ \\
\hline & & $\begin{array}{l}\text { Lack of specific information platform for } \\
\text { EL } R_{56}\end{array}$ \\
\hline
\end{tabular}

\section{Evaluation Mode}

According to the index system framework of ELR for natural disasters, using the method of Synthesizing Evaluation of Multiple Indexes, evaluation model for ELR was established as follows:

$$
\begin{aligned}
& \mathrm{R}=\sum_{\mathrm{i}=1}^{\mathrm{m}} \mathrm{R}_{\mathrm{i}} * \mathrm{~W}_{\mathrm{i}} \\
& \mathrm{R}_{\mathrm{i}}=\sum_{\mathrm{j}=1}^{\mathrm{n}} \mathrm{R}_{\mathrm{ij}} * \mathrm{~W}_{\mathrm{ij}}
\end{aligned}
$$

Among them, $\mathrm{R}$ represents the value of target layer indicator in this index system, used to indicate the overall risk of ELMS, the bigger the value is, indicating that the higher the risk level is. $\mathrm{R}_{\mathrm{i}}(\mathrm{i}=1, \ldots, 5)$ respectively are evaluation value indicating the indicators on factor layer, $\mathrm{R}_{\mathrm{ij}}(\mathrm{i}=1, \ldots, 5 ; \mathrm{j}=4,5$,or 6 ) represent evaluation value of indicators on index layer. $\mathrm{W}_{\mathrm{i}}$ and $\mathrm{W}_{\mathrm{ij}}$ respectively express the weight in each corresponding layer. Detailed evaluation method sees FCE below.

\section{E. Evaluation Method: Fuzzy Comprehensive Evaluation}

Fuzzy Comprehensive Evaluation (FCE) is a fuzzy mathematics-based comprehensive evaluation method, in which synthetic fuzzy relations theory is used to quantify various factors. By building a fuzzy class, it will quantify indicators that reflect the fuzzy evaluated matter. It's a combination of qualitative and quantitative evaluation method [22]. Analytical Hierarchy Process (AHP) is also a combination of qualitative and quantitative analysis method for decision-making. It decomposes a complex problem into a number of levels and factors, and then calculates weight for different program after comparison among various factors. In FCE, AHP is mainly used to determine the weights of various influencing factors. In this paper, FCE method was used to evaluate the evaluating index system of ELR, so as to achieve the early-warning and forecasting of the potential risk.

Steps of FCE are as follows:

1) Confirm the factor set $R$. The multifactor FCE model of ELRAIS was set up as Tab.2. According to Tab.2, the factor set is expressed to 2 layers: the target level $\mathrm{R}=\left\{\mathrm{R}_{1}, \mathrm{R}_{2}, \mathrm{R}_{3}, \mathrm{R}_{4}, \mathrm{R}_{5}\right\}$; the factor level $\mathrm{R}_{1}=\left\{\mathrm{R}_{11}\right.$, $\left.\mathrm{R}_{12}, \mathrm{R}_{13}, \mathrm{R}_{14}\right\} ; \mathrm{R}_{2}=\left\{\mathrm{R}_{21}, \mathrm{R}_{22}, \mathrm{R}_{23}, \mathrm{R}_{24}, \mathrm{R}_{25}\right\} ; \ldots \mathrm{R}_{5}=\left\{\mathrm{R}_{51}\right.$, $\left.\mathrm{R}_{52}, \mathrm{R}_{53}, \mathrm{R}_{54}, \mathrm{R}_{55}, \mathrm{R}_{56}\right\}$.

2) Confirm the appraisal set $V$ and assign its $U$. The evaluating set is a set of different evaluation results. According to the probability of risk occurring, ELR can be divided into different risk grades. This paper utilizes an evaluation of 5 grades, see Tab.3. $\mathrm{V}=\left(\mathrm{V}_{1}, \mathrm{~V}_{2}, \mathrm{~V}_{3}, \mathrm{~V}_{4}\right.$, $\left.\mathrm{V}_{5}\right)=($ Extremely risk, rather risk, middle risk, light risk, almost not risk). Differentiates score about grades are: $\mathrm{U}=\left(\mathrm{U}_{1}, \mathrm{U}_{2}, \mathrm{U}_{3}, \mathrm{U}_{4}, \mathrm{U}_{5}\right)=(100,80,60,40,20)$.

TABLE IV.

GRADES OF EMERGENCY LOGISTICS RISKS

\begin{tabular}{|c|c|c|}
\hline Risk grade V & $\begin{array}{c}\text { Value range } \\
\mathbf{U}\end{array}$ & $\begin{array}{c}\text { Description of the probability } \\
\text { of risk occurrence }\end{array}$ \\
\hline Extremely riskV $V_{1}$ & $80 \sim 100$ & Extremely probably occur \\
\hline Rather riskV & $60 \sim 80$ & Probably occur \\
\hline Middle riskV $_{3}$ & $40 \sim 60$ & May occur \\
\hline Light riskV & Might occur \\
\hline Almost not riskV $_{5}$ & $20 \sim 40$ & Almost will not occur \\
\hline
\end{tabular}

3) Confirm the weight set $W$ of evaluating index. Weight is the important yardstick to reflect influence degree of every evaluating index. The paper adopted AHP to fix the weight. To give each indicator different weights, and the fuzzy weight set of each indicator is:

$\mathrm{W}=\left(\mathrm{W}_{1}, \mathrm{~W}_{2}, \mathrm{~W}_{3}, \mathrm{~W}_{4}, \mathrm{~W}_{5}\right) ; \mathrm{W}_{\mathrm{i}}=\left(\mathrm{W}_{\mathrm{i} 1}, \ldots, \mathrm{W}_{\mathrm{ij}}\right),\{(\mathrm{i}, \mathrm{j})=(1,4),(2$ $, 5),(3,4),(4,4),(5,6)\}$;

$$
\text { And, } \sum_{\mathrm{i}=1}^{5} W_{\mathrm{i}}=1, \sum_{\mathrm{j}=1}^{\mathrm{n}} W_{\mathrm{ij}}=1
$$

4) Confirm the evaluation matrix $R$. In this research, the matrix is a two -layer model, the first layer $R$, the second layer $\mathrm{R}_{\mathrm{i}}$. According to the grades of logistics risks $\mathrm{V}$ in Table3, experts will mark $\mathrm{R}_{\mathrm{il}}$ for different risks from $V_{1}$ to $V_{5}$, combined with the actual investigating result of the practice, which make up the single factor appraisal matrix $\mathrm{R}_{\mathrm{i}}$, namely:

$$
R_{i}=\mid \begin{array}{ccccc}
R_{i 11} & R_{i 12} & R_{i 13} & R_{i 14} & R_{i 15} \\
R_{i 21} & R_{i 22} & R_{i 23} & R_{i 24} & R_{i 25} \\
\cdots \cdots & \cdots & & \\
R_{i n 1} & R_{i n 2} & R_{i n} 3 & R_{i n} 4 & R_{i n}
\end{array}
$$

5) Analyze a single element: the subset $R_{i}$ of element set $R$ could be denoted by fuzzy vector $U_{i}=\left\{V_{i 1}, V_{i 2}\right.$, $\left.\mathrm{V}_{\mathrm{i} 3}, \ldots, \mathrm{V}_{\mathrm{in}}\right\}$. For the given $\mathrm{Ri}, \mathrm{U}_{\mathrm{i}}$, the single element 
evaluating vector could be drawn, i.e. $B_{i}=R_{i} \cdot U_{i}$. The same method, $\mathrm{R}$ will be made up.

6) Evaluate comprehensively. The factor level $R_{i}$ can be denoted by fuzzy vector $\mathrm{W}_{\mathrm{ij}}$ and $\mathrm{R}_{\mathrm{ij}}, \mathrm{R}_{\mathrm{i}}=\mathrm{W}_{\mathrm{i}} \cdot \mathrm{R}_{\mathrm{i}}=$ $\left(\mathrm{W}_{\mathrm{i} 1}, \ldots, \mathrm{W}_{\mathrm{in}}\right) \cdot\left(\mathrm{R}_{\mathrm{il}}, \mathrm{R}_{\mathrm{i} 2}, \ldots, \mathrm{R}_{\mathrm{in}}\right)^{\mathrm{T}}, \mathrm{i}=1,2,3,4,5 ; \mathrm{n}=1,2,3,4$ or $\mathrm{n}=1,2,3,4,5$ or $\mathrm{n}=1,2,3,4,5,6$. Then, the comprehensive appraisal value of $\mathrm{R}$ can be calculated by $\mathrm{R}=\mathrm{W} \cdot \mathrm{B}=\left(\mathrm{W}_{1}\right.$, $\left.\mathrm{W}_{2}, \mathrm{~W}_{3}, \mathrm{~W}_{4}, \mathrm{~W}_{5}\right) \cdot\left(\mathrm{R}_{1}, \mathrm{R}_{2}, \mathrm{R}_{3}, \mathrm{R}_{4}, \mathrm{R}_{5}\right)^{\mathrm{T}}$. According to the section which the result on fuzzy comprehensive evaluation $\mathrm{R}$ locates in (table 3), the risk level of ELR is confirmed.

\section{F. Case Analysis}

\section{1) Basic Information about Yushu Earthquake and the} Emergency Logistics for it

A 7.1-magnitude earthquake attacked Yushu County, Qinghai Province on April 14, 2010. Up to April 20, 2046 people had been killed by the earthquake and 12,135 people were injured [23]. There were a lot of heavy difficulties to carry out emergency logistics for Yushu earthquake, because it was the largest scale of earthquake relief so far in the plateau region above the altitude of 4,000 meters. This emergency logistics was by only a fragile transport route, away from city supports, and lack of rescue forces, equipments and materials.

2) Evaluation of ELR for Yushu Earthquake

a. Confirm the appraisal set and evaluation matrix:According to the actual ELR condition for Yushu Earthquake, 7 experts in China were invited to judge the grade of each index of each level. Take the indicator 'Resources supporting risk $R_{5}$ ' as an example, Tab. 4 is the value range of this indicator. Each expert marked each term according to actual control level and integrated their results. The integration is $\mathrm{R}_{5}$

$$
\mathrm{R}_{5}=\left|\begin{array}{ccccc}
0.6 & 0.3 & 0.1 & 0 & 0 \\
0.4 & 0.4 & 0.1 & 0.1 & 0 \\
0.5 & 0.3 & 0.2 & 0 & 0 \\
0.2 & 0.2 & 0.3 & 0.2 & 0.1 \\
0.3 & 0.3 & 0.2 & 0.1 & 0.1 \\
0.2 & 0.4 & 0.2 & 0.2 & 0
\end{array}\right|
$$

So, $\mathrm{B}_{5}=\mathrm{R}_{5} \cdot \mathrm{U}=(90,82,90,64,72,72)^{\mathrm{T}}$.

b.Confirm the weight: The rational index weight would reflect the significance of the risks indicated by each warning index. According to the actual conditions and the experts' suggestions, AHP was used to confirm the weight of each index.

$\mathrm{W}=(0.20,0.21,0.18,0.14,0.27)$;

$\mathrm{W}_{1}=(0.35,0.30,0.10,0.25)$;

$\mathrm{W}_{2}=(0.15,0.25,0.30,0.20,0.10)$;

$\mathrm{W}_{3}=(0.20,0.25,0.20,0.35)$.

$\mathrm{W}_{4}=(0.40,0.30,0.15,0.15)$;

$\mathrm{W}_{5}=(0.25,0.20,0.15,0.10,0.15,0.15)$.

c.Evaluation of the single factor $R_{5}$ :According to the algorithm, we could get:

$\mathrm{R}_{5}=\mathrm{W}_{5} \cdot \mathrm{B}_{5}=(0.25,0.20,0.15,0.10,0.15,0.15) \cdot(90,82,90,64,7$ $2,72)^{\mathrm{T}}=80.4$. It's the evaluation result of the risk status of 'Resources Supporting Risk'. It suggested that the logistics resources supporting risk of Yushu Earthquake be in 'rather worse/ probably occur' status.

TABLE V.

VALUE RANGE OF INDICATOR $\mathrm{R}_{5}$

\begin{tabular}{|l|c|c|c|c|c|}
\hline \multirow{2}{*}{ Value } & \multicolumn{5}{|c|}{ Comment } \\
\cline { 2 - 6 } & $\begin{array}{c}\text { Extremely } \\
\text { risk } U_{1}\end{array}$ & $\begin{array}{c}\text { Rather } \\
\text { risk } U_{2}\end{array}$ & $\begin{array}{c}\text { Middle } \\
\text { risk } U_{3}\end{array}$ & $\begin{array}{c}\text { Light risk } \\
U_{4}\end{array}$ & $\begin{array}{c}\text { Almost not } \\
\text { risk } U_{5}\end{array}$ \\
\cline { 2 - 6 } & 100 & 80 & 60 & 40 & 20 \\
\hline $\begin{array}{l}\text { Continuous } \\
\text { secondary disasters } \\
\text { and bad weather } \mathrm{R}_{51}\end{array}$ & Weakest & Weaker & General & Strong & Strongest \\
\hline $\begin{array}{l}\text { Insufficient means of } \\
\text { transport } \mathrm{R}_{52}\end{array}$ & Worst & Worse & General & Better & Best \\
\hline $\begin{array}{l}\text { Damaged degree of } \\
\text { transport channel } \\
\mathrm{R}_{53}\end{array}$ & Weakest & Weaker & General & Strong & Strongest \\
\hline $\begin{array}{l}\text { Shortage of } \\
\text { emergency funds } \\
\text { and materials } \mathrm{R}_{54}\end{array}$ & Worst & Worse & General & Better & Best \\
\hline $\begin{array}{l}\text { Breakdown of } \\
\text { communication \& } \\
\text { information } \\
\text { networksR }\end{array}$ & Worst & Worse & General & Better & Best \\
\hline $\begin{array}{l}\text { Lack of specific } \\
\text { information platform } \\
\text { for EL } \mathrm{R}_{56}\end{array}$ & Worst & Worse & General & Better & Best \\
\hline
\end{tabular}

d.Comprehensive evaluation: The same method could be used to confirm values of each index, and based on which we could confirm the comprehensive result of the overall ELR level of Yushu Earthquake:

$\mathrm{R}=\mathrm{W} \cdot \mathrm{B}=(0.20,0.21,0.18,0.14,0.27) \cdot(72.2,58.5,70.0,50$. $6,80.4)^{\mathrm{T}}=68.4$. As the result $\mathrm{R}$ fall into $(60,80]$, it can be confirmed that the ELR level of Yushu Earthquake was in 'rather worse/ probably occur' status.

\section{CONCLUSIONS}

Five categories of risks exist in the operating process of emergency logistics, respectively are decision-making risk, dispatching \& commanding risk, organizing \& coordinating risk, executing \& controlling risk and resources supporting risk. These risks would lead to arrival delays, quantity lacks and quality damage of rescuing supplies by affecting the time efficiency, space efficiency, staff efficiency and supplies efficiency. The research of questionnaire survey offered an objective support for theoretical mechanism and index system establishment.

Among these 5 risks, environment and transportation risks in the resources supporting risk are uncontrollable which can only be adapted passively or taken efforts to improve in the long term. Decision-making risk can be controlled by strengthening early warning management or improve the decisive-maker's quality and experience. Dispatching \& commanding risk can be partially controlled by perfect systems and mechanisms. Organizing \& coordinating risk needs to be reduced by strengthening the scientificity of organization's establishment or coordinated by strengthening the communication. As for executing \& controlling risk, reliable logistic technology and equipment as well as 
higher information level are effective ways to reduce the risk level.

In the risk prevention, decision-making risk and organizing \& coordinating risk should be controlled strictly. Specific measures are suggested: Firstly, the decision-making and organizing \& coordinating process should be controlled by assessment, to guarantee a proper organization and coordination in order to improve the logistics efficiency. Special manners should be taken to control the timeliness of procurement, normative of procurement and rationality of logistic nodes' distribution. Secondly, special actions should be taken in the construction of transportation channels and communication equipment in the cities where disasters break out frequently and seriously. Preparation and prevention works on transportation channels' destroy and communication system's breakdown should be strengthened, while emergency routes and spare communication equipment should be planned or prepared in advance. At last, relevant civil affairs departments are intended to prepare more completed EL early warming plans and dispatch the government and military forces quickly to cooperate actively for disasters once breaking out.

The establishment of evaluating index system for ELR can acquaint the state controllers with potential risks, and confirm doable approaches to decrease risk rate according to actual index value. The establishment of this system was based on a comprehensive definition of the connotation and classification of ELR, and was a theoretical exploration under the guideline of Evaluating Management Theory. It could be served as the premise and criteria for emergency administration and logistics organization to identify the potential risks and judge the risk level and help to formulate risk plan or emergency schemes in advance. Yet, in this paper there still exist improvements on the established index system and applied evaluating methods, with further research in a broader empirical range.

\section{REFERENCES}

[1] Ming-Chih.Tsai, Ying-So Su, "Political risk assessment on air logistics hub developments in Taiwan," Journal of Air Transport Management, 2002, (8).

[2] Kimberly A Killmer Hollister, "A Risk/Cost Framework for Logistics Policy Evaluation: Hazardous Waste Management," Journal of Business \& Economic Studies, 2002, 8(1), pp. 23-30.

[3] Li Junjun, "Research on risk avoidance in the process of logistics services," Storage Transportation \& Preservation of Commodities, 2002, (1), pp. 19-22

[4] G M Giaglis,I Minis,A Tatarakis, "Minimizing logistics risk through real-time vehicle routing and mobile technologies," International Journal of Physical Distribution \& Logistics Management, 2004, 34(9), pp. 749-764

[5] Huang Benxiao,Cheng zuhao, "Discuss on risk avoidance in of logistics enterprise," Commercial Economy Studies, 2003, (18), pp. 16-17.

[6] Su Qi; Zhao Yifei, "Study on Control of Logistics Risk from the Angle of Risk Management," Logistics Sci-Tech, 2007, 09, pp. 30.
[7] Chen Xiaojun. The risk management of large-scale manufacturing enterprise logistics system. Shanghai Jiaotong University, 2006.

[8] Huang Jianzhu. Assessment study on the risk of manufacturing enterprise logistics system. Shanghai Maritime University, 2006.

[9] G E Appleguist, J F Pekny, G V Reklaitis,"Risk and uncertainty in managing chemical manufacturing supply chains," Computers and Chemical Engineering,2000,(24), pp. 211-2 222.

[10] Yuan Jiafeng, "Analysis on outsourcing risk of retail chain logistic,"Reformation \& Strategy, 2004, (6), pp. 13-15.

[11] Chen Weijian. Research and practice on customs logistics risk management. Huazhong University of science and technology, 2006.

[12] Peng Yulan," "The Third Party Logistics and its Risk Analysis," Commercial Research, 2004, (24) , pp. 147-150.

[13] Xiao Fengpin, Xu Zhengping, "Moral risk analysis on the third party logistics enterprise,"China Procurement and Transportation, 2006, (1), pp. 107-108.

[14] Wang Zhengfeng, Wang Xicheng, "Study on risk assessment of the fourth party logistics,"Market Modernization, 2006, (1), pp. 100 101.

[15] Joseph L Cavinato, "Supply chain logistics risk: From the back room to the board room, "International Journal of Physical Distribution \& Logistics Management, 2004, 34(5), pp. 383-385.

[16] Liu Xiaoqun, "Logistics outsourcing's motivation, risk and its management,"Commercial Economics Review, 2004, (1), pp. 63-65.

[17] Zhong Wei, etc, "Research on Formation Mechanism and Prevention of Logistics Outsourcing Risk,"China Safety Science Journal, 2005, (1), pp. 55-58.

[18] Zeng Xiangyun, "Study on the Cooperation Risk in 3PL and the Risk Prevention," China Business and Market, 2004, (7).

[19] Chen Fen. Study on the risk of global supply chain disruption, Ocean University of China, 2007.

[20] Zhou Yu. Research on the Emergency Logistics Risk Analysis Based on the BP Neural Network, Dalian Maritime University, 2009.

[21] ZhaoYong,Feng Shaojuan,Liu Jia, "Risk Analysis of Emergency Logistics,'Logistics Technology,2006(29), pp. 09 13.

[22] Zheng Jian. Research on Evaluating System of Logistics Outsourcing in Risk. DMU, Mar.2007.

[23] The death toll rose to 193 and 2046 were injured in Yushu earthquake. [EB/OL].Wuhan: Dachu net (2010-04-21) [2010-04-20].http://hb.qq.com/a/20100420/004212 .

Qi Cheng, female, born in Wuhan, Hubei, China, December 1976; Ph.D. in Management, Wuhan University of Technology, 2010; Lecturer; Main field of study: Risk and forewarning management; logistical management, marketing management.

She has been a Teacher in Wuhan University of Technology, Wuhan, Hubei, China since April, 2002, and ever parted in writing the published book Logistics Management(Beijing: KeXue Press,2008).Current research interests focus on Disaster Emergency Logistics \& Risk and Forewarning Management.

Lei Yu, male, born in Xiangfan, Hubei, China, June 1990; undergraduate in Management, Wuhan University of Technology; Main field of study: Risk and forewarning management; logistical management, marketing management. 